\title{
Occurrence of Hypocalcaemia in Admitted Neonates in NICU
}

\section{Nisha Jyoti Shrestha', Moon Thapa ${ }^{1}$, Kalpana Upadhaya Subedi', Subhana Thapa Karki², Saroja Adhikari ${ }^{3}$ and Anuradha Pandey ${ }^{4}$}

${ }^{1}$ Neonatology unit, International Friendship Children's Hospital, Maharajgunj, Kathmandu, Nepal

${ }^{2}$ Endocrine Unit, International Friendship Children's Hospital, Maharajgunj, Kathmandu, Nepal

${ }^{3}$ Digital Data System for Development, Kathmandu, Nepal

${ }^{4}$ Nursing In-charge, Neonatal Intensive Care Unit, International Friendship Children's Hospital, Maharajgunj, Kathmandu, Nepal

\begin{abstract}
Introduction: Hypocalcaemia is common metabolic manifestation in neonates and associated with both maternal and foetal conditions. Hypocalcaemia is labeled if term neonate's total serum calcium is $<8 \mathrm{mg} /$ $\mathrm{dl}$ and preterm has $<7 \mathrm{mg} / \mathrm{dl}$. Association of neonatal and maternal hypovitaminosis $\mathrm{D}$ is very common. .

Methods: One year retrospective study was conducted in a tertiary level private children hospital of Kathmandu, Nepal from 2018 June to 2019 July. Total 299 cases were selected and serum calcium were sent and analysed for its association with illness, associated maternal hypovitaminosis D and other relevant maternal tests.

Result: Among 686 NICU cases, calcium level was sent for 299 cases. Among these, 254 were term and 45 were preterm babies and male to female ratio was $4: 1$. Mean calcium in term babies were $8.6 \mathrm{mg} / \mathrm{dl}$ and in preterm it was $8.1 \mathrm{mg} / \mathrm{dl}$. Hypocalcaemia was found in $19 \%$ of cases with mean calcium level was $7.1 \pm 0.84 \mathrm{mg} / \mathrm{dl}$ and severe hypocalcaemia accounted for $12 \%$. There was no significant presence of hypocalcaemia in relation to gestation of newborn ( $p$ value 0.798 ). We found higher incidence of late onset hypocalcemia than early onset hypocalcemia but was not of statistical significance ( $p$ value 0.771 ). Associated disease were perinatal asphyxia, congenital heart diseases and prematurity. Among 27 late onset hypocalcaemia, 22\% had hypovitaminosis D both in neonates and mother.

Conclusions: Neonatal hypocalcaemia is a common condition associated with sick newborns. In late hypocalcaemia both newborn and mother should be screened for associated lab tests like vitamin D, magnesium, PTH as there may be association between the two.

Key words: Hypovitaminosis D; Late onset Hypocalcaemia; Neonates
\end{abstract}

Correspondence: Nisha Jyoti Shrestha, Neonatology unit, International Friendship Children's Hospital, Maharajgunj, Kathmandu, Nepal. Email: nishajyoti@hotmail.com

DOI: $10.3126 / \mathrm{mjsbh.v20i2.35505}$

Submitted on: 2020-03-10

Accepted on: 2019-12-09 


\section{INTRODUCTION}

Neonates are the most vulnerable age group accounting for majority percentage of infant mortality in Nepal. ${ }^{1,2}$ The leading causes of death in neonates are septicaemia, perinatal asphyxia, preterm and its complications. They present with various presentations like poor feeding, lethargy, fever or hypothermia, abnormal body movement, yellowish discolouration, respiratory symptoms etc. Most of the time neonates present with vague and non-specific symptoms. We send various tests which will directly help us in the diagnosis and treatment and some of these tests will establish the baseline data. Among frequently done tests, serum calcium is one of the common one. It is routinely sent for various conditions like prematurity, perinatal asphyxia, seizures and seizure like activities. While in some diseases, we monitor serum calcium like before and after starting phototherapy. Hence, calcium level should be monitored in high risk cases and sometimes routinely in many diseases where they might mimic common symptoms like lethargy vomiting, poor muscle tone, abdominal distention, poor feeding or irritability. ${ }^{3-5}$

Hypocalcaemia is one of the common metabolic abnormalities manifested in neonates. ${ }^{3-5}$ It is potentially a life-threatening condition whose prevalence varies by gestational age, maternal and infant co-morbidities, and perinatal factors. Neonatal hypocalcaemia is classified according to its time of presentation. Early onset hypocalcemia is hypocalcemia which manifests within 72 hours of birth and delayed onset manifests after three days of birth. Delayed or late onset neonatal hypocalcaemia has poorer prognosis and has lengthy treatment duration.

Delayed or late onset hypocalcaemia may be due to various complex disorders. Mostly it is found in association with low vitamin D level (both baby and mother), abnormal maternal calcium, abnormal parathyroid hormone (PTH), low magnesium etc. So, in late onset neonatal hypocalcemia, extensive workup may be required which may result in prolonged hospital stay and difficult management. ${ }^{6-9}$ Hence, this study was conceptualised to study the incidence, classification and correlation of neonatal hypocalcemia with relevant maternal blood values.

\section{METHODS}

A retrospective study was conducted for a period of one year in a tertiary level private children hospital of Kathmandu, Nepal from 2018 June to 2019 July. During the study period, 686 neonates were admitted and among them, serum calcium was sent in 299 cases. Their serum calcium levels were noted, analysed and correlated with relevant manternal tests. All neonates whose calcium level was sent were selected as cases. Calcium were sent as routine test for some newborns like foetal distress, preterm, prior to phototherapy etc. and some were sent for being symptomatic with seizure and jitteriness. In order to maximise the sample size, all the cases whose calcium was sent were included, despite the status of prior receiving of intravenous calcium outside the hospital. Those babies who had incomplete data were excluded from the study. Variables such as gestational age, birth weight, perinatal history, examination findings and relevant lab investigations were recorded in predesigned proforma. All the cases had their first serum calcium level sent at time of admission and any abnormal level for corresponding gestation age were repeated 24 to 48 hours later. Calcium level for term neonates was considered low if total serum calcium is $<8 \mathrm{mg} / \mathrm{dl}$ and for preterm $<7 \mathrm{mg} / \mathrm{dl}^{6}{ }^{6}$ Those with low calcium level were categorised as early onset and late onset, depending upon their time of presentation. Among those with late onset hypocalcaemia, other relevant investigations were sent. Total $3 \mathrm{ml}$ blood was drawn and evaluated for blood calcium and phosphorus (fully automatic method by Selectra machine), magnesium (Spectrophotometry) and PTH and vitamin $\mathrm{D}_{3}$ test (CLIA) and results were recorded in the proforma. Daily vital signs, occurrence of seizures, urine frequency and other related issues were also noted. SPSS Version 20 was used to analyse the data. Chi square test was used to see the significant association among variables. $P$ value of $<0.05$ was considered significant.

\section{RESULT}

Total 686 cases were admitted in NICU during the study period. Among total admitted cases, calcium level was sent for 299 cases. Among which 254 


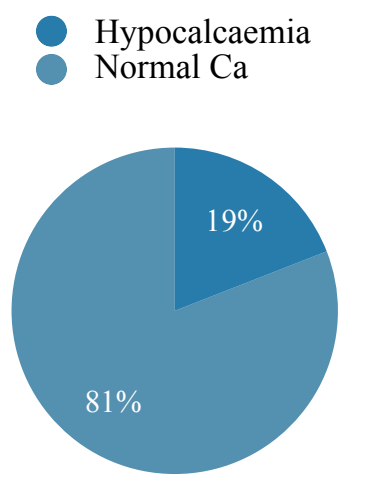

Figure 1. Serum Calcium among admitted neonates

were term babies and 45 were preterm babies. Among the cases, there were more male babies in comparison to female babies. Even in babies with hypocalcaemia, male to female ratio was $4: 1$. Among these, 127 presented within 72 hours of life and 172 presented after 72 hours of life. Among 299 cases whose calcium was sent, mean calcium in term babies was $8.6 \mathrm{mg} / \mathrm{dl}$, and in preterm babies, it was $8.1 \mathrm{mg} / \mathrm{dl}$. Hypocalcaemia was found in $19 \%$ of cases (Figure 1) with mean calcium level was $7.1 \pm 0.84 \mathrm{mg} / \mathrm{dl}$ (term hypocalcaemia mean $7.1 \pm 0.85 \mathrm{mg} / \mathrm{dl} \&$ preterm $6.7 \pm 0.25 \mathrm{mg} / \mathrm{dl})$. Among 19\% babies with hypocalcemia, various range of calcium level was depicted in figure 2 . $12 \%$ babies had severe hypocalcaemia.

Various associated diseases of newborn with hypocalcemia have been shown in fig 3 . We found hypocalcaemia in $26 \%$ of foetal distress cases and $15 \%$ in prematurity. We also noted highest number of hypocalcaemia in children with congenital heart diseases (38\%). Status of PTH, vitamin D, phosphorus and magnesium in children with late onset neonatal hypocalcaemia is shown in figure 4 .

As shown in fig 4, 27 cases of LoNH, six (22\%) had low vitamin $\mathrm{D}_{25}$ level. Among those six cases with low vitamin $\mathrm{D}_{25}$, maternal serum calcium,

Table 1. Low calcium association with preterm and term

\begin{tabular}{|l|r|r|r|r|}
\hline & $\begin{array}{l}\text { Low } \\
\text { calcium }\end{array}$ & $\begin{array}{l}\text { Normal } \\
\text { calcium }\end{array}$ & $\begin{array}{l}\text { Chi } \\
\text { square } \\
\text { test }\end{array}$ & P value \\
\hline Term & 54 & 200 & 0.0654 & 0.798 \\
Preterm & 3 & 42 & & \\
Total & 57 & 242 & & \\
\hline
\end{tabular}

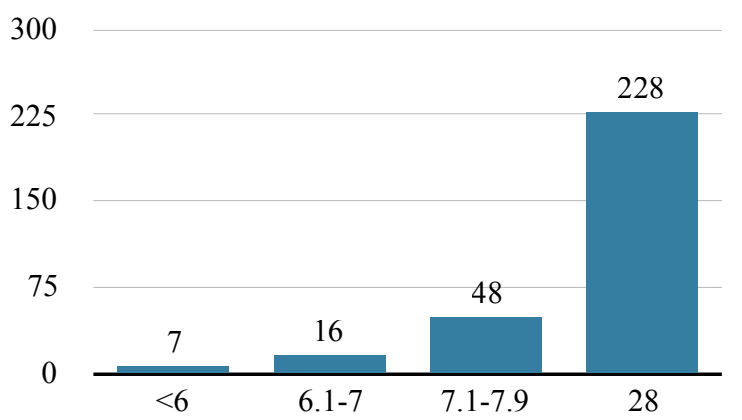

Figure 2. Various level of calcium among admitted neonates

phosphorus, PTH, magnesium and vitamin D25 were sent. Our study found that among all six cases, there was also maternal hypovitaminosis D but normal calcium, phosphorus, magnesium and PTH.

\section{DISCUSSION}

We analysed 299 babies whose calcium level was sent. Among these, 254 were term babies and 45 were preterm babies. Similarly, there were 219 male babies and 80 were female babies. In babies with hypocalcaemia, male female ratio was $4: 1$. This higher incidence of male babies may be due to the fact that ours being patriarchal society, more preference is given to male children and thus more male children get medical attention and thus get admitted more. This fact has been demonstrated in other studies too. ${ }^{11,12}$

We had found mean serum calcium level of $8.6 \mathrm{mg} /$ $\mathrm{dl}$ for term babies and $8.1 \mathrm{mg} / \mathrm{dl}$ for preterm babies. Our result is also in congruence with another study by Shrestha D et al. ${ }^{18}$ In this study, the authors had done cord blood screening showing mean calcium of $8.6 \pm 0.9 \mathrm{mg} / \mathrm{dl}$. Another study done by Do HJ et $\mathrm{al}^{8}$ also showed mean calcium level of $8.6 \mathrm{mg} / \mathrm{dl}$. We had noted hypocalcaemia in $19 \%$ of cases with

Table 2. Low calcium association with time of presentation

\begin{tabular}{l|r|r|r|r|} 
& Hypocalcaemia & $\begin{array}{c}\text { Normal } \\
\text { calcium }\end{array}$ & $\begin{array}{c}\text { Chi } \\
\text { square } \\
\text { test }\end{array}$ & $\begin{array}{c}\text { P } \\
\text { value }\end{array}$ \\
\hline Early case & 30 & 97 & 0.08464 & 0.771 \\
Late case & 27 & 145 & & \\
Total & 57 & 242 & & \\
\hline
\end{tabular}




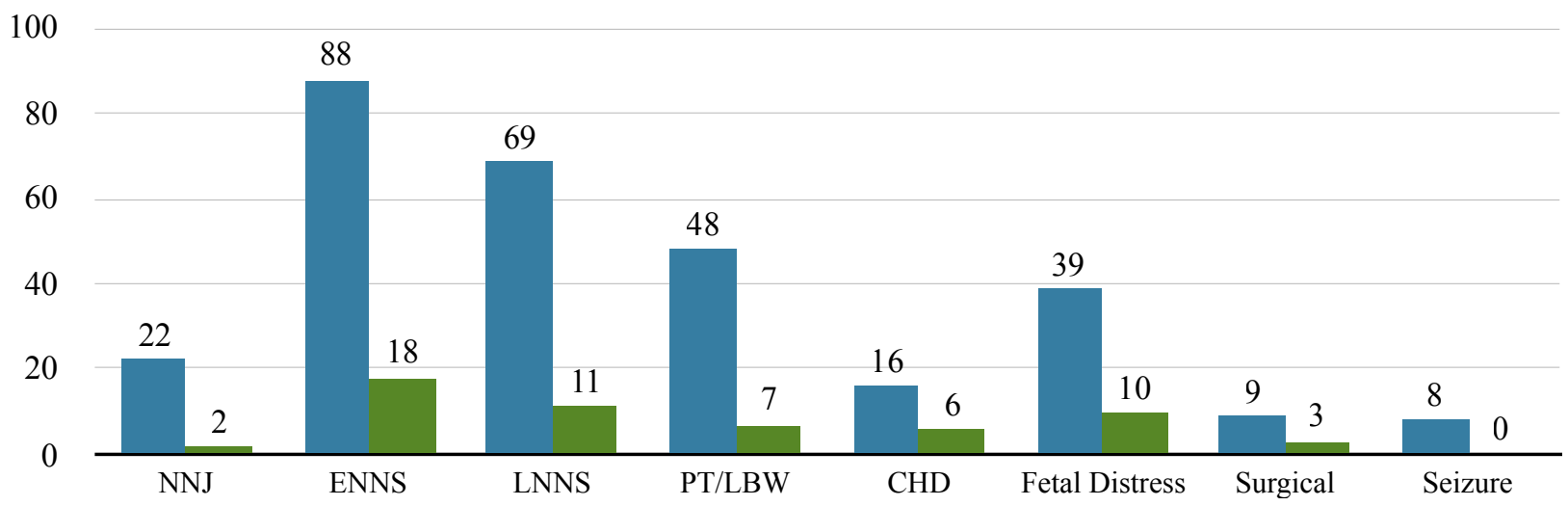

Figure 3. Occurrence of hypocalcaemia in association with various diseases of newborn.

mean calcium of $7.1 \pm 0.84 \mathrm{mg} / \mathrm{dl}$. This finding is consistent with similar study conducted by Khalesi $\mathrm{N}$ et al. ${ }^{7}$

There was no significant difference in incidence of hypocalcemia in preterm babies in comparison to term babies ( $p$ value 0.798 ) in our study. This finding of ours is in contradictition to general findings in other studies done in the past. ${ }^{3-5}$ However, study done by Elsary AY et al. ${ }^{11}$ also had larger proportion of term babies in comparison to preterm babies like ours. Since our hospital is a referral hospital, substantial number of babies with perinatal asphyxia and preterm babies who presented to our set up had already received prophylactic IV calcium. This fact may have resulted in lesser number of hypocalcaemia in both term and preterm babies. So number of actual hypocalcaemia in term and preterm might have been larger than we had found in this study.

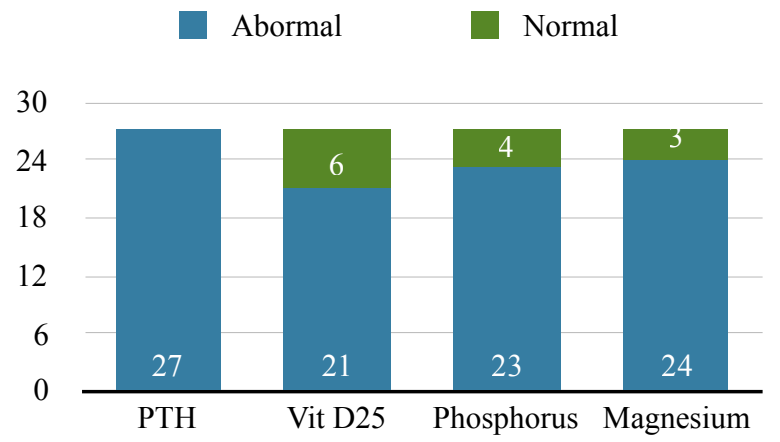

Figure 4: Associated lab results in neonates with late onset hypocalcaemia
We had found similar number of early and late onset hypocalcemia in our study with no significant difference ( $p$ value 0.771 ). Generally, there is more presentation of early onset hypocalcaemia than late onset hypocalcemia. However, some studies have shown more frequent late onset hypocalcemia than early onset. ${ }^{11,12}$ This may be explained by the fact that these studies were from middle east countries where clothing culture is different leading to large incidence of vitamin D deficiency in mothers resulting in increase in late onset hypocalcaemia in newborns. In contrary, we have higher incidence of perinatal asphyxia and preterm deliveries and thus, there is higher possibility of early onset hypocalcaemia in our set up. At the same time, ours being a referral centre, most of the cases would have already received intravenous calcium before reaching our set up, it is very difficult to get the true incidence of hypocalcemia.

Among various associated diseases, we found hypocalcaemia in $26 \%$ of foetal distress cases and $15 \%$ in prematurity cases. This finding of ours is consistent with other studies done in the past. ${ }^{16,17}$ Surprisingly our study showed high incidence of hypocalcaemia with cases of congenital heart disease (38\%). This finding could be explained by the fact that seriously ill babies generally have hypocalcemia ${ }^{15}$ and most babies in our study were critically ill. Similarly, most babies with genetic abnormalities have higher incidence of associated cardiac anomalies ${ }^{13}$ or associated anomalies of 
third and fourth pharyngeal pouch ${ }^{14}$ and they are prone to have associated hypocaclemia as well.

Out of 27 cases of late onset hypocalcemia, six (22\%) babies had low vitamin $\mathrm{D}_{25}$ level in both neonates and as well as mother. We had small data to show the association of maternal vitamin $\mathrm{D}$ with neonatal hypocalcaemia and low vitamin $\mathrm{D}$ in neonates. However, our result is consistent with various studies done in abroad ${ }^{7,11,12}$ as well as in Nepal. ${ }^{18}$ These studies had showed close relation of neonatal hypocalcaemia with maternal low vitamin D level. This may be the result of clothing culture, food habit, skin colour as well as similar races. However, we need larger, multicentric, prospective studies on symptomatic cases to learn more about detrimental effect of low maternal vitamin $\mathrm{D}_{25}$ on newborns.

\section{CONCLUSIONS}

Neonatal hypocalcaemia is a common metabolic condition which is commonly associated with sick newborns. In late hypocalcaemia both newborn and mother should be screened for associated lab tests like vitamin D, magnesium, PTH.

\section{ACKNOWLEDGEMENT}

To all the staffs of Neonatology unit, International Friendship Children's Hospital, Maharajgunj, Kathmandu, Nepal.

To cite this article: Shrestha NJ, Thapa M, Subedi KU, Karki ST, Adhikari S, Pandey A. Occurrence of Hypocalcaemia in admitted neonates in NICU. MJSBH. 2021; 20(2):156-61.

Conflict of Interest: None declared

\section{REFERENCES}

1. Ministry of Health - MOH/Nepal, New ERA/Nepal, and ICF. 2017. Nepal Demographic and Health Survey 2016. Kathmandu, Nepal: MOH/Nepal, New ERA/Nepal, and ICF. Available from https://www.dhsprogram.com/pubs/ pdf/fr336/fr336.pdf

2. Central Bureau of Statistics (CBS) 2020. Nepal Multiple Indicator Cluster Survey 2019, Survey Findings Report. Kathmandu, Nepal: Central Bureau of Statistics and UNICEF Nepal. Available from https://www.unicef.org/nepal/ media/9076/file/NMICS_2019___Key_findings.pd

3. Abrams SA. Abnormalities of Serum Calcium and Magnesium, Manual of Neonatal Care, $6^{\text {th }}$ Edition, Wolters Kluwer/Lippincott William \& Wilkins; 2008. pg. 550

4. Greenbaum LA. Nutrition, Chapter 51 Rickets \& Hypervitaminosis D, Nelson Textbook of Paediatrics 20th Edition, ELSEVIER; 2016. Pg. 337.

5. Rubin LP. Disorders of Calcium and phosphorus Metabolism, Avery's disease of the Newborn 9th edition, ELSEVIER Saunders; 2012. Pg1255-1273.

6. Vuralli D. Clinical Approach to Hypocalcemia in Newborn Period and Infancy: Who Should Be Treated? Int J Pediatr. 2019 Jun 19;2019:4318075. DOI: 10.1155/2019/4318075

7. Khalesi N, Bahaeddini SM and Shariat M.. Prevalence of Maternal Vitamin D Deficiency in Neonates with Delayed Hypocalcaemia, Acta Medica Iranica. 2012; 50(11):740-5. PMID:23292625.

8. Do HJ, Park JS, Seo JH, Lee ES, Park CH, Woo HO, et al. Neonatal Late-onset Hypocalcaemia: Is There Any Relationship with Maternal Hypovitaminosis D? Pediatr Gastroenterol Hepatol Nutr. 2014 March;17(1):47-51. DOI: $10.5223 /$ pghn.2014.17.1.47

9. Cho WI, Yu HW, Chung HR, Shin CH, Yang SW, Choi CW, et al. Clinical and laboratory characteristics of neonatal hypocalcaemia. Ann Pediatr Endocrinol Metab. 2015;20:86-91. DOI: 10.6065/apem.2015.20.2.86

10. Thomas SDC, Fudge AN, Whiting M, Coates PS. The correlation between third-trimester maternal andnewbornserum25-hydroxy-vitamin D in a selected South Australian group of newborn samples, BMJ Open. 2011;1: e000236. DOI:10.1136/bmjopen-2011-000236 
11. Elsary AY, Elgameel AA, Mohammed WS, Zaki OM, Taha SA. Neonatal hypocalcaemia and its relation to vitamin D and calcium supplementation. Saudi Med J. 2018;39(3): 247-53. DOI: 10.15537/smj.2018.3.21679

12. Thomas TC, Smith JM, White PC and Adhikari S. Transient Neonatal Hypocalcaemia: Presentation and Outcomes. Paediatric. 2012;129(6);3-11. DOI:10.1542/peds.2011-2659

13. Rayannavar A, Levitt KLE, Crowley TB, Lessig M, Grand K, Goldmuntz E, et al. Association of hypocalcaemia with congenital heart disease in 22q11.2 deletion syndrome. Am J Med Genet A. 2018 Oct;176(10):2099-103. DOI: 10.1002/ajmg.a.40495

14. Freedom RM, Rosen FS, Nadas AS. Congenital cardiovascular disease and anomalies of the third and fourth pharyngeal pouch. Circulation. 1972 Jul;46(1):165-72. DOI: 10.1161/01.cir.46.1.165. PMID: 5039819.

15. Kelly A, Levine MA. Hypocalcemia in the critically ill patient. J Intensive Care Med. 2013;28(3):166-77. DOI: $10.1177 / 0885066611411543$.

16. Thakur J, Bhatta NK, Singh RR, Poudel P, Lamsal M, Shakya A. Prevalence of electrolyte disturbances in perinatal asphyxia: a prospective study. Ital J Pediatr. 2018 May 21;44(1):56-9. DOI: 10.1186/s13052-018-0496-7

17. Tsang RC, Chen I, Hayes W, Atkinson W, Atherton H, Edwards N. Neonatal hypocalcemia in infants with birth asphyxia. J Pediatr. 1974 Mar;84(3):428-33. DOI: 10.1016/s0022-3476(74)80733-X.

18. Shrestha D, Budhathoki S, Pokhrel S, Sah AK, Shrestha RK, Raya GB, et al. Prevalence of vitamin D deficiency in pregnant women and their babies in Bhaktapur, Nepal. BMC Nutr. 2019;5(1);31-9. DOI: 10.1186/ s40795-019-0294-7 